\title{
PERUBAHAN TATA RUANG RUMAH TIPE KECIL DAN PENGARUHNYA TERHADAP ASPEK KESEHATAN PENGHUNI
}

(Kasus Studi: Rumah Sederhana Sehat di Depok Jawa Barat)

\author{
Ashadi $^{1}$, Anisa $^{2}$, Nelfiyanti $^{3}$ \\ 1 Jurusan Arsitektur, Fakultas Teknik, Universitas Muhammadiyah Jakarta \\ ${ }^{2}$ Jurusan Arsitektur, Fakultas Teknik, Universitas Muhammadiyah Jakarta \\ ${ }^{3}$ Jurusan Teknik Industri, Fakultas Teknik, Universitas Muhammadiyah Jakarta \\ Jl. Cempaka Putih Tengah 27 Jakarta Pusat 10510 \\ ashadihadiwinoto@yahoo.co.id, anisa@ftumj.ac.id, nelfiyanthi@gmail.com
}

\begin{abstract}
ABSTRAK. Kesehatan menjadi aspek penting yang harus diperhatilkan dalam desain rumah. karena rumah yang sehat akan berdampak pada kenyamanan yang dirasakan oleh penghuni. Penelitian ini bertujuan untuk mengetahui perubahan tata ruang rumah tipe kecil $\leq 36 \mathrm{~m}^{2}$ dan pengaruh perubahan tersebut pada aspek kesehatan penghuninya. Kesehatan difokuskan pada sirkulasi udara dan cahaya (penghawaan dan pencahayaan) yang merupakan dua aspek penting pada kesehatan dalam rumah. Metode yang digunakan adalah metode deskriptif kualitatif dengan mengambil kasus secara purposif sampling. Hasil yang didapatkan dari penelitian ini adalah pada perubahan tata ruang rumah tipe kecil selalu ada ruang yang tidak mendapatkan pencahayaan secara maksimal. Arah perubahan pada rumah tipe kecil adalah ke arah samping, belakang dan depan sehingga sirkulasi udara dan cahaya yang awalnya dioptimalkan melalui halaman depan dan belakang menjadi terganggu. Upaya yang dilakukan adalah dengan membuat bukaan berupa jendela dan roster yang cukup lebar sehingga udara dan cahaya dapat masuk ke dalam ruangan. Namun untuk ruang yang tidak mendapatkan cahaya matahari secara langsung akan menjadi gelap dan lembab sehingga mempengaruhi kesehatan penghuninya.
\end{abstract}

Kata kunci: tata ruang, rumah, kesehatan

ABSTRACT. Health is become an important aspect which should be concerned in designing a house. Healthy house will affect to the conviniency of the occupants. This research is aimed to explore the transformation of house's layout of small house less than $36 \mathrm{~m}^{2}$ and the impact of the changes to the health aspect for occupants. Health aspect will be focused on air circulation and natural lighting which are very important aspects for health within house. A qualitative descriptive method has been conducted to analyse this research by taking some cases with purposive sampling. A significant result will be presented that the changes of house's layout of small house will affect to the existence of room which will not suplied by maximum natural lighting as well as good air circulation. The change direction of small house is to the side direction, backwards and forward, thus air circulation and natural lighting which at the beginning will be optimized through rear side and front side will be interrupted. Efforts will be made by providing opened wall such as wide windows and roster, to circulate the air and natural lighting inside the house. For some rooms which will be not supported to get direct natural lighting and air circulation, the rooms will be uncomfortable for occupants, because it will be dark and humid for some reasons and will affect to the health of the occupants.

Keywords: layout, house, health

\section{PENDAHULUAN}

Kesehatan merupakan aspek yang penting dalam sebuah rumah tinggal. Tidak hanya nyaman digunakan untuk beraktivitas tetapi sebuah rumah juga harus sehat. Aspek kesehatan yang dibahas dalam penelitian ini didasarkan pada pedoman umum Rumah Sederhana sehat. Menurut Pedoman Umum Rumah Sederhana Sehat tahun 2002, rumah sebagai tempat tinggal yang memenuhi syarat kesehatan dan kenyamanan dipengaruhi oleh
3 aspek yaitu pencahayaan, penghawaan serta suhu udara dan kelembaban dalam ruangan. Aspek-aspek tersebut merupakan dasar atau kaidah perencanaan rumah sehat dan nyaman. [1]

Upaya yang dapat dilakukan untuk memenuhi aspek kesehatan dapat dimaksimalkan melalui pencahayaan dalam ruangan yang sesuai dengan aktivitas, penghawaan alami dapat masuk ke semua ruangan dan mempunyai sirkulasi yang baik, serta ruangan yang tidak 
lembab. Aspek kesehatan penghuni dapat ditelusuri melalui wawancara kepada penghuni rumah. Salah satu indikasi yang dapat digunakan untuk mengetahui kenyamanan dapat dicapai salah satunya dengan pencahayaan alami. Kenyamanan tersebut meliputi kenyamanan visual dan kenyamanan termal. Kenyamanan visual berkaitan dengan cahaya alami yang membantu manusia untuk menggunakan penglihatannya. Pencahayaan yang sesuai dengan kebutuhan dan kegiatan yang sedang dilakukan akan memberikan kenyamanan visual. Sedangkan kenyamanan termal berkaitan dengan cahaya matahari yang memberikan energi panas ke dalam ruangan. [2]

Faktor kenyamanan bukan satu-satunya peran yang diberikan oleh cahaya alami pada manusia. Cahaya alami yang dihasilkan oleh matahari juga berpengaruh pada tubuh manusia dan berperan dalam menjaga kesehatan manusia. Secara umum sebuah rumah tinggal memiliki kebutuhan ruang yang relatif sama satu dengan yang lain. Baik sebuah rumah sangat sederhana maupun rumah mewah. Perbedaan yang ada lebih pada spesifikasi kegiatan, kebutuhan luasan dan volume ruang serta berbagai furniture dan peralatan yang ada di dalamnya. [2]

Rumah tipe kecil diambil sebagai kasus penelitian dengan pertimbangan bahwa desain rumah tipe kecil juga harus memperhatikan aspek kesehatan. Karena rumah tidak akan terasa nyaman jika hanya fungsional semata tetapi juga harus sehat. Lokasi penelitian dilakukan di Depok, Jawa Barat. Penelitian ini difokuskan pada perubahan pada rumah tipe kecil dan pengaruhnya pada aspek kesehatan penghuninya.

\section{KETENTUAN RUMAH SEDERHANA SEHAT} [1]

Rumah sederhana sehat yaitu rumah yang dibangun dengan menggunakan bahan bangunan dan konstruksi sederhana akan tetapi masih memenuhi standar kebutuhan minimal dari aspek kesehatan, keamanan dan kenyamanan dengan mempertimbangkan dan memanfaatkan potensi lokal meliputi potensi fisik seperti bahan bangunan, geologis dan iklim setempat serta potensi sosial budaya seperti arsitektur lokal dan cara hidup.

Kebutuhan ruang minimal menurut perhitungan dengan ukuran standar minimal adalah $9 \mathrm{~m}^{2}$ atau standar ambang dengan angka $7,2 \mathrm{~m}^{2}$ per-orang. Sebagai konsepsi dasar kedua perhitungan tersebut masih digunakan dengan tetap mempertimbangkan bentuk akhir rumah paska pengembangan. Sehingga dari hasil perhitungan diatas didapat luas bangunan awal adalah $21 \mathrm{~m}^{2}$ dengan pertimbangan dapat dikembangkan menjadi $36 \mathrm{~m}^{2}$.

Ada beberapa ketentuan rumah sederhana sehat yaitu:

1. Kebutuhan minimal penampilan dan ruang dalam

Kebutuhan ruang per-orang dihitung berdasarkan aktivitas dasar manusia di dalam rumah. Aktivitas seseorang tersebut meliputi aktivitas tidur, makan, kerja, duduk, mandi, kakus, cuci dan masak serta ruang gerak lainnya. Dari hasil kajian, kebutuhan ruang per-orang adalah $9 \mathrm{~m}^{2}$ denagn perhitungan ketinggian rata-rata langitlangit adalah $2.80 \mathrm{~m}$.

Rumah sederhana sehat memungkinkan penghuni untuk dapat hidup sehat dan menjalankan kegiatan hidup sehari-hari secara layak. Kebutuhan minimum ruangan pada rumah sederhana sehat perlu memperhatikan beberapa ketentuan sebagai berikut: (1) kebutuhan luas [per jiwa; (2) kebutuhan luas perkepala keluarga (KK); (3) kebutuhan luas bangunan per kepala keluarga (KK); (4) kebutuhan luas lahan per unit bangunan.

2. Kebutuhan kesehatan dan kenyamanan

Rumah sebagai tempat tinggal yang memenuhi syarat kesehatan dan kenyamanan dipengaruhi oleh 3 aspek yaitu pencahayaan, penghawaan serta suhu udara dan kelembaban dalam ruangan. Aspek-aspek tersebut merupakan dasar atau kaidah perencanaan rumah sehat dan nyaman.

a. Pencahayaan. Matahari sebagai potensi terbesar yang dapat digunakan sebagai pencahayaan alami pada siang hari. Pencahayaan yang dimaksud adalah penggunaan terang langit dengan ketentuan sebagai berikut: (1) cuaca dalam keadaan cerah dan tidak berawan; (2) ruangan kegiatan mendapatkan cukup banyak cahaya; (3) ruang kegiatan mendapatkan distribusi cahaya secara merata. Kualitas pencahayaan alami siang hari yang masuk ke dalam ruangan ditentukan oleh:

- Kegiatan yang membutuhkan daya penglihatan (mata) 
- Lamanya waktu kegiatan yang membutuhkan daya penglihatan (mata)

- Tingkat atau gradasi kekasaran dan kehalusan jenis pekerjaan

- Lubang cahaya minimun persepuluh dari luas lantai ruangan

- Sinar matahari langsung dapat masuk ke ruangan minimun 1 jam setiap hari

- Cahaya efektif dapat diperoleh dari jam 08.00 sampai dengan jam 16.00

b. Penghawaan. Udara merupakan kebutuhan pokok manusia untuk bernafas sepanjang hidupnya. Udara akan sangat berpengaruh dalam menentukan kenyamanan pada bangunan rumah. Kenyamanan akan memberikan kesegaran terhadap penghuni dan terciptanya rumah yang sehat, apabila terjadi pengaliran atau pergantian udara secara kontinyu melalui ruangan-ruangan serta lubanglubang pada bidang pembatas dinding atau partisi sebagai ventilasi. Agar diperoleh kesegaran udara dalam ruangan dengan cara penghawaan alami,maka dapat dilakukan dengan memberikan atau mengadakan peranginan silang dengan ketentuan sebagai berikut:

- Lubang penghawaan minimal 5\% dari luas lantai

- Udara yang mengalir masuk sama dengan volume udara yang mengalir ke luar ruangan

- Udara yang masuk tidak berasal dari asap dapur atau bau kamar mandi/ WC

c. Suhu udara dan kelembaban. Rumah dinyatakan sehat dan nyaman apabila suhu udara dan kelembaban udara ruangan sesuai dengan suhu tubuh manusia normal. Suhu udara dan kelembaban ruangan sangat dipengaruhi oleh penghawaan dan pencahayaan. Penghawaan yang kurang atau tidak lancar akan menjadikan ruangan terasa pengap atau sumpek dan akan menimbulkan kelembaban tinggi dalam ruangan. Untuk mengatur suhu udara dan kelembaban normal untuk ruangan dan penghuni dalam melakukan kegiatannya, perlu memperhatikan: i. Keseimbangan penghawaan antara volume udara yang masuk dan keluar

ii. Pencahayaan yang cukup pada ruangan denagn perabotan tidak bergerak

iii. Menghindari perabotan yang menutupi sebagian besar luas lantai ruangan.

3. Kebutuhan Minimal Keamanan dan Keselamatan

Pada dasarnya bagian-bagian struktur pokok untuk bangunan rumah tinggal sederhana adalah: pondasi, dinding (dan kerangka bangunan), atap serta lantai. Sedangkan bagian-bagian lain seperti langit-langit, talang dan sebagainya merupakan estetika struktur bangunan saja.

\section{KRITERIA RUMAH SEHAT [3]}

Farida mengungkapkan ada 7 Kriteria Rumah Sehat yaitu:

1. Kering. Rumah dikondisikan dengan membangun sistem bangunan yang dikonstruksi dengan lingkungan dalam ruangan yang terkontrol. Bisa dilakukan dengan menjaga agar sistem saluran air, saluran pembuangan terjaga dengan baik. Begitu pun masalah perembesan dan kebocoran rumah, hendaknya diatur agar tidak terjadi.

2. Bersih. Sistem bangunan yang dimiliki memungkinkan agar rumah bebas kotoran, debu, asap serta kontaminan lainnya. Rumah yang berada di dekat jalan raya jelas berbeda penangannya dengan rumah yang ada di kompleks persawahan.

3. Aman. Rumah hendaknya dibangun dengan bentuk, fungsi, dan peralatan yang aman bagi penghuni. Konsep ergonomis di setiap piranti hendaknya juga dipikirkan dengan matang. Sisi keamanan adalah faktor yang penting, demi menghindari terjadinya kecelakaan di dalam maupun di sekitar rumah

4. Bebas Kontaminasi. Gunakan cat rumah dan produk-produk bangunan yang aman dan tidak mengganggu kesehatan. Jauhi penggunaan formaldehida untuk meminimalisir kontaminasi anggota keluarga.

5. Memiliki Ventilasi. Ventilasi berfungsi untuk memperlancar pertukaran udara segar. Standardnya harus ada di setiap ruangan. 
6. Bebas dari hewan pengganggu. Penghuni hendaknya menjaga agar setiap sudut rumah bebas dari hewan pengganggu seperti tikus, kecoa, cicak, dll. Hewanhewan ini selalu berusaha untuk mencari makanan dan sarang di dalam rumah sehingga anda harus benar-benar ekstra bekerja keras untuk mengenyahkannya.

7. Terawat. Rumah yang sehat adalah rumah yang setiap elemennya terawat dan terpelihara dengan baik. Para penghuni rumah hendaknya mengatur jadwal khusus untuk saling berbagi tugas melakukan tugas ini demi kepentingan bersama.

Menurut Kementerian Kesehatan Republik Indonesia Rumah sehat harus memenuhi 7 kriteria, yaitu atap berplafon, dinding permanen (tembok/papan), jenis lantai bukan tanah, tersedia jendela, ventilasi cukup, pencahayaan alami cukup, dan tidak padat huni (lebih besar atau sama dengan $8 \mathrm{~m} 2 /$ orang). Data survey didapatkan sebanyak $24,9 \%$ rumah penduduk di Indonesia sudah termasuk dalam kriteria rumah sehat. Provinsi yang paling rendah persentasenya yaitu Nusa Tenggara Timur $(7,50 \%)$, sedangkan provinsi yang persentasenya paling tinggi yaitu Kalimantan Timur $(43,60 \%)$ selanjutnya Kepulauan Riau $(42,7 \%)$. [4]

Pada tahun 2010 persentase rumah tangga dengan kualitas fisik air minum termasuk kategori baik (tidak keruh, tidak berwarna, tidak berasa, tidak berbusa, dan tidak berbau) sebesar $90 \%$, di perkotaan $94,2 \%$ dan di perdesaan $85,6 \%$. Persentase kualitas fisik air minum yang keruh sebesar $6,9 \%$, berwarna $4 \%$, berasa $3,4 \%$,berbusa $1,2 \%$, dan berbau sebesar $2,7 \%$. Persentase rumah tangga dengan sumber utama air minum yang berada di dalam rumah sebesar $53,3 \%$. Provinsi dengan persentase tertinggi di Sulawesi Selatan (66,9\%), dan yang terendah di Provinsi Nusa Tenggara Timur (16,5\%). Rumah tangga dengan sumber utama air minum yang berjarak $\leq 10$ meter dari rumah sebesar $28,5 \%$, yang berjarak 11 - 100 meter sebesar 13,7\%; yang berjarak $101-1.000$ meter sebesar $3,5 \%$, dan yang jaraknya lebih dari 1.000 meter sebesar 0,9\%. [4]

\section{PENCAHAYAAN DALAM RUMAH TINGGAL}

\section{Desain Bukaan untuk Memasukkan Cahaya}

Secara umum cahaya dapat dimasukkan ke dalam ruangan melalui tiga bagian bangunan yaitu: bagian samping, bagian atas dan bagian bawah. Ketiga bagian tersebut mengacu pada sisi-sisi bangunan yang memungkinkan dijadikan akses bagi masuknya cahaya alami. Ketiga bagian tersebut mengacu pada sisi-sisi bangunan [2]

Menurut Nurwulandari Ada 3 cara yang dapat digunakan untuk mendesain bukaan untuk cahaya yaitu:

(1) Tempatkan bukaan sesuai fungsi ruang;

(2) Jangan berlebihan dalam hal ukuran;

(3) Refleksi atau pantulan dari permukaan bidang.

1. Tempatkan Bukaan Sesuai Fungsi Ruang. Ada dua hal yang kita dapatkan dari matahari yaitu cahaya dan panas. Cahaya bisa dipakai untuk pengganti lampu penerangan khususnya siang hari. Untuk daerah iklim tropis, panas akibat radiasi matahari sedapat mungkin dikendalikan agar tidak merusak atau menimbulkan ketidaknyamanan. Berikut adalah daftar beberapa ruang dengan cahaya yang dibutuhkan. Tempatkan ventilasi yang sesuai dengan fungsi setiap ruang dan manfaatkan cahayanya untuk mendukung aktivitas di dalam ruang tersebut. Cahaya yang masuk ke dalam ruang dapat diatur sedemikian rupa dengan memperhatikan arah hadap/ orientasi bukaan (jendela). Angka radiasi setiap orientasi memiliki besar yang berbeda (lihat tabel radiasi). Sebaiknya, selain itu tinggi perletakan dan bentuk bukaan perlu diperhatikan agar sudut cahaya matahari yang tajam di pagi atau sore hari tidak mengganggu. Dalam mendesain bukaan untuk memasukkan cahaya harus disesuaikan dengan fungsi ruang yang ada di dalamnya. Karena setiap ruang dengan aktivitas tertentu membutuhkan cahaya yang berbedabeda. [5] 
Tabel 1. Jenis Ruang dan Pencahayaan

\begin{tabular}{|c|c|c|}
\hline Jenis ruang & Jenis pencahayaan yang sesuai & $\begin{array}{l}\text { Letak bukaan yang } \\
\text { disarankan }\end{array}$ \\
\hline Ruang Tidur & Pencahayaan pagi (matahari pagi) & Tenggara sampai timur laut \\
\hline Gudang, kamar mandi & $\begin{array}{l}\text { Matahari sore (paling tinggi tingkat } \\
\text { radiasinya) agar tak lembab dan jamur } \\
\text { terbunuh }\end{array}$ & Barat atau timur \\
\hline $\begin{array}{l}\text { Ruang keluarga, ruang } \\
\text { makan, ruang tamu }\end{array}$ & $\begin{array}{l}\text { Tingkat aktivitas tinggi, perlu cahaya } \\
\text { hangat }\end{array}$ & $\begin{array}{l}\text { Barat laut atau barat daya } \\
\text { atau utara dan selatan }\end{array}$ \\
\hline $\begin{array}{l}\text { Dapur, ruang kerja } \\
\text { (komputer) }\end{array}$ & $\begin{array}{l}\text { Butuh cahaya yang adem agar panas } \\
\text { yang masuk tidak menaikkan suhu ruang }\end{array}$ & Utara dan selatan \\
\hline
\end{tabular}

Sumber : Nurwulandari, 2003

2. Jangan berlebihan. Bukaan untuk memasukkan cahaya harus disesuaikan dengan kebutuhan. Berlebihan dalam memasukkan cahaya justru akan menimbulkan efek negatif. Menurut data SNI, banyaknya lubang cahaya ideal dalam suatu ruang dinyatakan oleh nilai WWR (Wall Window Ratio). WWR adalah perbandingan luas jendela dengan luas seluruh dinding luar pada orientasi yang ditentukan. Dari ketentuan ini nilai idealnya adalah $20 \%$ dari luas dinding keseluruhan. Contoh perhitungan ukuran ruang $4 \mathrm{~m} \times 4 \mathrm{~m}$ $=16 \mathrm{~m}^{2}$. Maka luas bukaan cahaya ideal adalah $20 \% \times 16 \mathrm{~m}^{2}=3,2 \mathrm{~m}^{2}$. Luas itu bisa dipenuhi dengan jendela ukuran $1 \mathrm{~m} \times 1,6 \mathrm{~m}$ (dua buah) atau jendela ukuran $2 \mathrm{~m} \times 1,6 \mathrm{~m}$ (satu buah).[5]

3. Refleksi atau pantulan dari permukaan bidang. Merancang bukaan untuk cahaya juga perlu memperhatikan warna dan detail permukaan bidang yang terkena sinar. Warna cerah lebih banyak memantulkan sinar daripada warna gelap. Warna putih akan memantulkan $70 \%-80 \%$ sinar matahari; warna muda (biru muda, kuning muda, hijau muda, coklat muda) 20\%-60\%; warna gelap (hitam, coklat, abu-abu tua) memantulkan $<20 \%$ (Sumber: SNI 03-6197-2000). Agar terlihat terang dan mengurangi panas, terapkan warna-warna muda.

\section{Pengaruh Cahaya Pada Kesehatan Manusia [6]}

Dalam perancangan bangunan, peletakan lubang jendela perlu diusahakan agar pada sisi utara dan selatan bangunan lebih banyak. Sedangkan perletakan jendela pada sisi timur dan barat bangunan sebaiknya dihindari. Terutama pada sisi barat bangunan timbul masalah karena cahaya matahari dari barat cukup panas dan menyengat. Salah satu pengaruh cahaya alam pada bangunan adalah suhu dari intensitas sinar matahari yang langsung dapat meningkatkan suhu dinding akibat konduksi dan suhu ruangan bila sinar matahari langsung masuk pada ruangan.

Tanggapan manusia terhadap cahaya rupanya berbeda-beda dalam masing-masing kebudayaan. Untuk kebanyakan manusia, cahaya merah berarti hangat, sedangkan cahaya biru mengakibatkan perasaan dingin. Karena pencahayaan matahari di daerah tropis mengandung gejala samping dengan sinar panas, maka di daerah tersebut manusia sering menganggap ruang yang agak gelap sebagai sejuk dan nyaman. Akan tetapi untuk melakukan kegiatan tertentu diadakan standar penyinaran alamiah maupun penerangan buatan terutama untuk ruang kerja. Walaupun demikian daya produksi meningkat jika pencahayaan berubah-ubah mengikuti perputaran waktu sehari. Penerangan buatan yang makin jauh dari jendela seolah-olah menggantikan kurangnya cahaya alam. Karena pencahayaan buatan dengan lampu dan sebagainya mempengaruhi kesehatan manusia, maka dibutuhkan pencahayaan alam yang terang, bebas kesilauan dan tanpa sinar panas. Untuk memenuhi tuntutan berlawanan ini, maka sebaiknya sinar matahari tidak diterima secara langsung melainkan sinar tersebut dicerminkan/ dipantulkan misalnya dalam air kolam (menghilangkan panasnya)

\section{METODOLOGI PENELITIAN}

Metode Deskriptif Kualitatif digunakan dalam penelitian ini untuk mendapatkan deskripsi mengenai perubahan tata ruang pada rumah tipe kecil dan pengaruhnya terhadap kesehatan penghuninya. Metode Kualitatif dipilih dengan pertimbangan bahwa pengaruh 
perubahan tata ruang terhadap kesehatan dapat diamati melalui pengamatan fisik dan dilengkapi dengan wawancara terhadap penghuninya. Metode ini digunakan dalam pengambillan data dan analisa untuk mendapatkan hasil yang komprehensif mengenai perubahan tata ruang dan pengaruh perubahan tersebut terhadap kesehatan penghuni.

Metode deskriptif bertujuan untuk mendapatkan gambaran atau deskripsi tentang suatu permasalahan yang akan diselesaikan. Pengertian deskriptif berdasarkan Kamus besar Bahasa Indonesia adalah suatu bentuk penelitian yang ditujukan untuk mendeskripsikan fenomena-fenomena yang ada, baik fenomena alamiah maupun fenomena buatan manusia. Fenomena itu bisa berupa bentuk, aktivitas, karakteristik, perubahan, hubungan, kesamaan dan perbedaan antara fenomena yang satu dengan fenomena lainnya. Bogdan dan Taylor dalam Moleong menyatakan bahwa metodologi kualitatif sebagai prosedur penelitian yang menghasilkan data deskriptif berupa kata-kata tertulis atau lisan dari orang-orang dan perilaku yang dapat diamati. [7]

Kota Depok dijadikan lokasi penelitian karena perkembangan pembangunan rumah sederhana yang sangat pesat. Lingkup materi yang diteliti meliputi materi fisik dan nonfisik. Materi fisik didapatkan berdasarkan pengamatan dan pengukuran. Sedangkan materi non fisik didapatkan dari hasil wawancara untuk mendapatkan pengaruh perubahan tata ruang terhadap kesehatan secara kualitatif. Obyek penelitian adalah rumah sederhana dengan luasan $\leq 36 \mathrm{~m}^{2}$ sesuai dengan Pedoman Umum Rumah Sederhana Sehat bahwa kebutuhan luas minimum bangunan untuk Rumah sederhana untuk 4 jiwa adalah $36 \mathrm{~m}^{2}$. Metode pengambilan obyek sebagai sampel penelitian adalah purposive sampling, yaitu pengambilan sampel dengan tujuan tertentu. Selanjutnya sampel dalam penelitian ini disebut sebagai kasus.

\section{HASIL DAN PEMBAHASAN}

\section{Hasil Pengamatan Lapangan}

Rumah yang dijadikan kasus penelitian berjumlah 3 rumah dengan rincian sebagai berikut :

(1) Rumah terletak di hook;

(2) Rumah terletak di tengah;

(3) Rumah terletak di tengah.

Ruangan pada rumah tipe kecil awalnya terdiri dari 1 ruang tamu, 2 kamar tidur, 1 dapur dan 1 kamar mandi. Perubahan tata ruang yang terjadi adalah dengan menambahkan ruangan lain yang diperlukan untuk menunjang aktivitas penghuni. Pada kasus 1, ada 3 ruangan yang ditambahkan yaitu ruang makan, ruang keluarga dan warung. Pada kasus 2 penambahan terdiri dari 1 ruang keluarha dan 1 ruang untuk bermain anak. Sedangkan pada kasus 3 penambahan ruang berupa ruang makan dan ruang keluarga. Arah perubahan pada rumah tersebut adalah arah samping dan belakang. Bagi rumah yang berada di hook, perubahan ke arah samping kemudian ke arah belakang. Sedangkan rumah yang terletak di tengah maka perubahan langsung ke arah belakang. (tabel 2 ) 
Tabel 2. Perubahan Ruang-ruang pada rumah tipe kecil

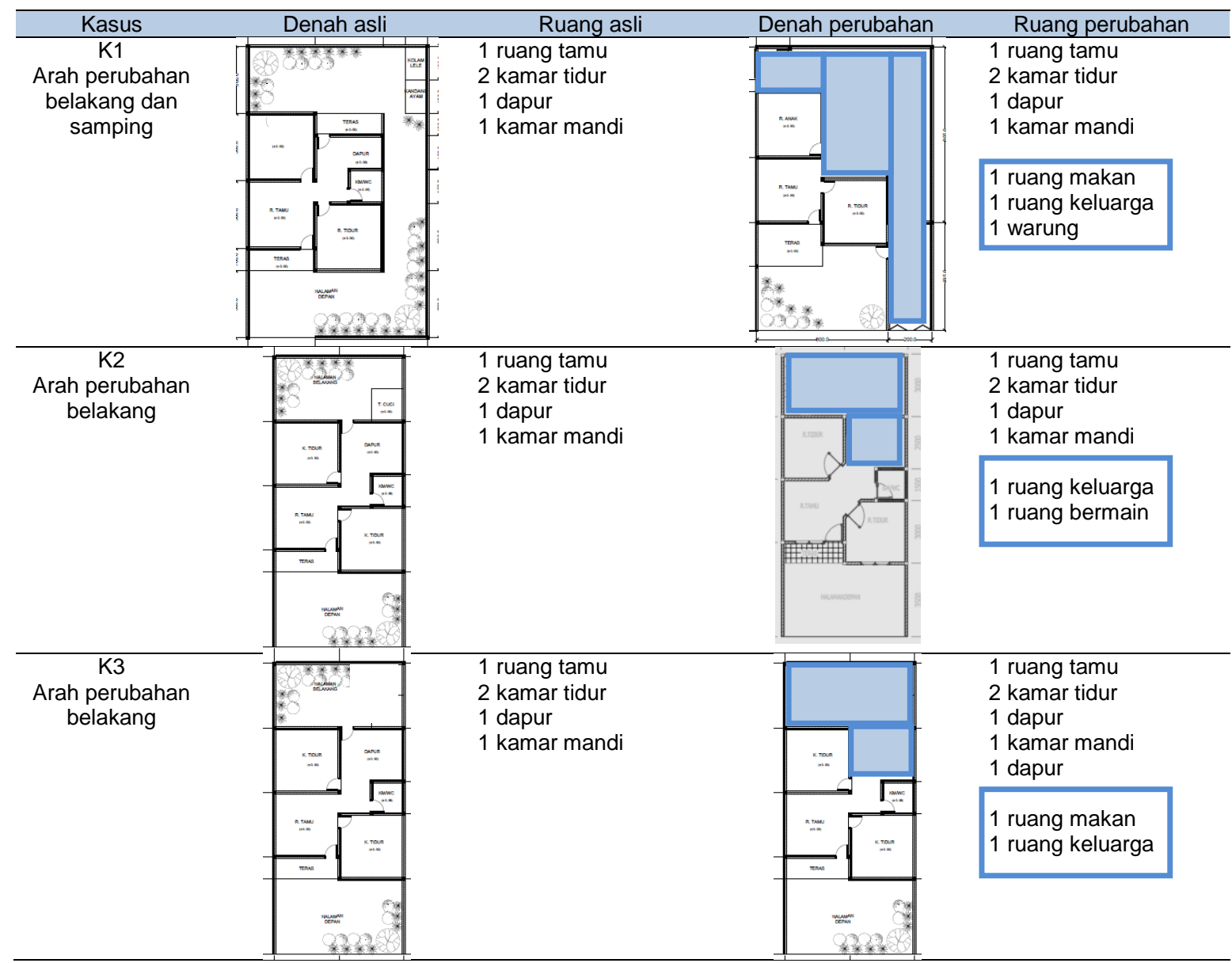

\section{ASPEK KESEHATAN DALAM RUMAH}

Aspek kesehatan yang dibahas dalam penelitian ini adalah pencahayaan, penghawaan dan kelembaban. Pencahayaan digunakan sebagai salah satu indikator kesehatan rumah tipe kecil dengan dua pertimbangan. Pertama, kesehatan dalam rumah dipengaruhi oleh banyaknya cahaya matahari (pencahayaan alami) yang masuk ke dalam ruangan karena cahaya matahari tidak hanya menerangi tetapi juga mengandung zat yang dapat mematikan kuman. Pertimbangan kedua yaitu pencahayaan akan mempengaruhi kenyamanan aktivitas di dalam ruang. Karena beragamnya aktivitas di dalam rumah yang membutuhkan intensitas cahaya berbedabeda.

Kebutuhan pencahayaan selain dipengaruhi oleh aktivitas yang dilakukan di dalam ruangan juga dipengaruhi oleh usia pengguna. Dapat dilihat pada literatur [4] dinyatakan bahwa kebutuhan cahaya setiap orang berbeda-beda tergantung pada: (1) usia; (2) ukuran obyek yang terlihat; dan (3) tingkat ketelitian/ kesulitan pekerjaan yang dilakukan. Dijelaskan juga bahwa orang yang berumur 60 tahun membutuhkan $15 x$ lebih tinggi tingkat cahaya dibanding anak umur 10 tahun. Jadi walaupun aktivitas yang dilakukan sama tetapi kalau manusia sebagai pelaku kegiatannya berbeda, tingkat pencahayaan yang dibutuhkan juga berbeda.

Penghawaan dan kelembaban dalam rumah juga merupakan aspek kesehatan yang tidak kalah penting. Penghawaan dan kelembaban berkaitan dengan sirkulasi udara dan elemen pendukungnya di dalam rumah. Pada rumah tipe kecil, elemen bangunan yang digunakan untuk memasukkan cahaya dan udara adalah sama. Wujud dari elemen tersebut adalah bukaan berupa jendela, jalusi, roster maupun lubang penghawaan yang lain.

Pengamatan tentang aspek kesehatan secara fisik dilakukan pada masing-masing kasus dilakukan 3 kali dalam 1 hari. Dengan jumlah kasus sebanyak 3 rumah maka total dilakukan pengamatan selama 9 kali. Pengamatan dilakukan saat cuaca cerah. Pengamatan 
tersebut dilakukan pagi hari (08.00), siang (12.00) dan sore (16.00). Pengamatan tentang pencahayaan dilakukan selama 3 kali untuk mendapatkan hasil yang akurat. Disamping itu pembatasan waktu dari jam 08.00 sampai 16.00 berdasarkan Pedoman Umum Rumah Sederhana sehat bahwa cahaya efektif dapat diperoleh dari jam 08.00 sampai 16.00 . pengamatan tentang penghawaan dan kelembaban dilakukan secara fisik yang dilengkapi dengan wawancara kepada penghuninya.

Desain asli rumah tipe kecil sudah mempertimbangkan aspek kesehatan yang cukup baik. Pada desain asli semua ruang mendapatkan cahaya matahari yang cukup untuk beraktivitas. Perkecualian pada kamar mandi kasus rumah yang terletak di tengah, tidak mendapatkan cahaya maksimal dan hanya mengandalkan bukaan yang ada di plafon. Hal ini terjadi karena posisi kamar mandi biasanya diapit dengan ruangan yang lain. Namun setelah terjadi perubahan pada tata ruang dengan penambahan beberapa ruang maka ada ruang-ruang yang tidak maksimal mendapatkan cahaya matahari karena terhalang oleh ruang lain. Ruang-ruang yang dimaksud misalnya ruang makan dan ruang keluarga.

Tabel 3. Distribusi cahaya dalam Ruang pada rumah tipe kecil

\begin{tabular}{|c|c|c|c|c|c|c|c|c|c|}
\hline \multirow{2}{*}{ Ruang } & \multicolumn{3}{|c|}{ pagi } & \multicolumn{3}{|c|}{ siang } & \multicolumn{3}{|c|}{ sore } \\
\hline & K1 & $\mathrm{K} 2$ & K3 & K1 & $\mathrm{K} 2$ & $\mathrm{~K} 3$ & K1 & $\mathrm{K} 2$ & $\mathrm{~K} 3$ \\
\hline Ruang Tamu & $\sqrt{\sqrt{ }}$ & $\sqrt{\sqrt{ }}$ & $\sqrt{\sqrt{ }}$ & $\sqrt{\sqrt{ }}$ & $\sqrt{\sqrt{ }}$ & $\sqrt{\sqrt{ }}$ & $\sqrt{\sqrt{ }}$ & $\sqrt{\sqrt{ }}$ & $\sqrt{\sqrt{ }}$ \\
\hline Kamar tidur 1 & $\sqrt{ } \sqrt{ }$ & $\sqrt{ } \sqrt{ }$ & $\sqrt{ } \sqrt{ }$ & $\sqrt{ } \sqrt{ }$ & $\sqrt{ } \sqrt{ }$ & $\sqrt{ } \sqrt{ }$ & $\sqrt{ } \sqrt{ }$ & $\sqrt{ } \sqrt{ }$ & $\sqrt{ } \sqrt{ }$ \\
\hline Kamar tidur 2 & $\sqrt{ }$ & $\sqrt{ }$ & $\sqrt{ }$ & $\sqrt{ }$ & $\sqrt{ }$ & $\sqrt{ }$ & $\sqrt{ }$ & $\sqrt{ }$ & $\sqrt{ }$ \\
\hline Dapur & $\sqrt{ } \sqrt{ }$ & $\sqrt{ } \sqrt{ }$ & $\sqrt{ } \sqrt{ }$ & $\sqrt{ } \sqrt{ }$ & $\sqrt{ } \sqrt{ }$ & $\sqrt{ } \sqrt{ }$ & $\sqrt{ } \sqrt{ }$ & $\sqrt{ }$ & $\sqrt{ }$ \\
\hline Kamar Mandi & $\sqrt{ }$ & $\sqrt{ }$ & $\sqrt{ }$ & $\sqrt{ }$ & $\sqrt{ }$ & $\sqrt{ }$ & $\sqrt{ }$ & $\sqrt{ }$ & $\sqrt{ }$ \\
\hline Ruang makan & $\sqrt{ } \sqrt{ }$ & & $\sqrt{ } \sqrt{ }$ & $\sqrt{ } \sqrt{ }$ & & $\sqrt{ } \sqrt{ }$ & $\sqrt{ }$ & & $\sqrt{ }$ \\
\hline Ruang keluarga & $\sqrt{ }$ & $\sqrt{ }$ & $\sqrt{ } \sqrt{ }$ & $\sqrt{ } \sqrt{ }$ & $\sqrt{ }$ & $\sqrt{ } \sqrt{ }$ & $\sqrt{ }$ & $\sqrt{ }$ & $\sqrt{ }$ \\
\hline Ruang bermain & & $\sqrt{ } \sqrt{ }$ & & & $\sqrt{ } \sqrt{ }$ & & & $\sqrt{ }$ & \\
\hline warung & $\sqrt{ } \sqrt{ }$ & & & $\sqrt{ } \sqrt{ }$ & & & $\sqrt{ } \sqrt{ }$ & & \\
\hline $\begin{array}{l}\text { Keterangan : } \\
\sqrt{ } \sqrt{ } \text { Seluruh ruanga } \\
\sqrt{ } \text { Sebagian }(1-1, \\
\text { - Gelap }\end{array}$ & $n g-$ & & & & & & & & \\
\hline
\end{tabular}

Menurut Kementerian Kesehatan Republik Indonesia Rumah sehat harus memenuhi 7 kriteria, yaitu atap berplafon, dinding permanen (tembok/papan), jenis lantai bukan tanah, tersedia jendela, ventilasi cukup, pencahayaan alami cukup, dan tidak padat huni (lebih besar atau sama dengan 8 m2/orang). Berdasarkan kriteria dari kemenkes tersebut maka ketiga rumah yang menjadi kasus studi sudah memenuhi kriteria. Dari tabel 3 dapat dilihat bahwa semua ruang sudah diupayakan mempunyai bukaan untuk memasukkan cahaya dan sirkulasi udara. Namun karena posisinya terhalang ruangan yang lain maka ada beberapa ruang yang hanya mendapatkan cahaya pada sebagian ruangnya. Contoh pada kamar tidur 2 yang terletak di belakang. Desain asli, kamar tidur 2 mendapatkan cahaya dan sirkulasi udara yang cukup dari halaman belakang. Setelah terjadi perubahan dengan menambahkan ruang pada bagian belakang maka kamar tidur 2 hanya mendapatkan cahaya yang masuk melalui ruang tamu.

Sedangkan aspek kesehatan berdasarkan sirkulasi udara, dapat diamati melalui bukaan yang ada pada semua ruang dan sirkulasi udara pada ruang yang diteliti. Sirkulasi udara terbaik adalah menggunakan cross ventilation atau ventilasi silang. Hal ini sudah diupayakan pada ruang-ruang yang ada dengan cara membuat ventilasi silang antara perletakan jendela dengan roster yang terletak di atas pintu. Pengamatan secara kualitatif mengenai sirkulasi udara di dalam ruang dapat dilihat pada tabel 4 dimana hampir semua ruang mendapatkan sirkulasi udara yang cukup melalui bukaan berupa pintu jendela maupun elemen yang lain (Tabel 6)

Tabel 4. Sirkulasi Udara di dalam Ruang

\begin{tabular}{|l|l|l|l|}
\hline Ruang & K1 & K2 & K3 \\
\hline Ruang Tamu & Baik & Baik & Baik \\
\hline Kamar tidur 1 & Baik & Baik & Baik \\
\hline Kamar tidur 2 & cukup & Cukup & cukup \\
\hline Dapur & baik & baik & Baik \\
\hline Kamar Mandi & cukup & cukup & Cukup \\
\hline Ruang makan & baik & & Baik \\
\hline Ruang keluarga & baik & Baik & Baik \\
\hline Ruang bermain & & Baik & \\
\hline warung & baik & & \\
\hline
\end{tabular}


Kelembaban merupakan aspek kesehatan yang penting karena ruang yang lembab akan membuat kuman cepat berkembang biak. Kelembaban juga bisa dirasakan dan diamati secara kualitatif oleh manusia. Biasanya ruang yang lembab karena tidak mendapatkan cahaya matahari secara langsung. Cahaya matahari terutama sore hari mempunyai radiasi yang tinggi sehingga sangat baik untuk mematikan kuman. Setelah melakukan pengamatan terhadap aspek pencahayaan, sirkulasi udara dan kelembaban pada rumah tipe kecil, langkah berikutnya adalah melakukan pengukuran terhadap bukaan yang digunakan untuk memasukkan cahaya yang sekaligus digunakan untuk sirkulasi udara dan mengurangi kelembaban di dalam rumah.

Menurut Farida, salah satu kriteria rumah sehat adalah memiliki ventilasi. Ventilasi berfungsi untuk memperlancar pertukaran udara segar. Standardnya harus ada di setiap ruangan. Menurut analisa di lapangan ventilasi tidak hanya harus ada di setiap ruangan namun juga harus diperhatikan posisinya. Misalnya dengan ventilasi silang. Hal lain yang perlu diperhatikan adalah dalam desain ventilasi harus dipertimbangkan luas ruang dan jangkauan yang bisa dicapai karena ventilasi atau bukaan pada rumah tipe kecil tidak hanya digunakan untuk memasukkan cahaya atau udara semata tetapi berfungsi ganda yaitu untuk memasukkan cahaya, untuk pertukaran udara dan untuk mengurangi kelembaban dalam ruang.

Selain itu untuk mengurangi kelembaban bisa dilakukan dengan memasukkan cahaya matahari secara langsung pada ruang-ruang yang lembab melalui berbagai sisi (samping dan atas).

Tabel 5. Kelembaban dalam ruang

\begin{tabular}{|l|l|l|l|}
\hline Ruang & K1 & K2 & K3 \\
\hline Ruang Tamu & Tidak lembab & Tidak lembab & Tidak lembab \\
\hline Kamar tidur 1 & Tidak lembab & Tidak lembab & Tidak lembab \\
\hline Kamar tidur 2 & Sedikit lembab & sedikit lembab & sedikit lembab \\
\hline Dapur & Tidak lembab & sedikit lembab & Sedikit lembab \\
\hline Kamar Mandi & Sedikit lembab & sedikit lembab & sedikit lembab \\
\hline Ruang makan & Tidak lembab & & Tidak lembab \\
\hline Ruang keluarga & Tidak lembab & Tidak lembab & Tidak lembab \\
\hline Ruang bermain & & Sedikit lembab & \\
\hline warung & Tidak lembab & & \\
\hline
\end{tabular}

Tabel 6. elemen bangunan yang digunakan untuk memasukkan cahaya dan sirkulasi udara serta kelembaban

\begin{tabular}{|c|c|c|c|c|c|c|}
\hline & Kasus 1 & ukuran & Kasus 2 & ukuran & Kasus 3 & ukuran \\
\hline \multirow[t]{3}{*}{ Ruang Tamu } & Pintu & $90 \times 210$ & Pintu & $90 \times 210$ & Pintu & $90 \times 210$ \\
\hline & Jendela & $130 \times 160$ & Jendela & $130 \times 160$ & Jendela & $130 \times 160$ \\
\hline & Roster & $20 \times 20$ (5 buah) & Roster & $20 \times 20$ (5 buah) & Roster & $20 \times 20(5 \mathrm{bh})$ \\
\hline \multirow[t]{3}{*}{ Kamar 1} & Pintu & $90 \times 210$ & Pintu & $90 \times 210$ & Pintu & $90 \times 210$ \\
\hline & Jendela & $130 \times 160$ & Jendela & $130 \times 160$ & Jendela & $130 \times 160$ \\
\hline & Roster & $20 \times 20$ & Roster & $20 \times 20$ & Roster & $20 \times 20$ \\
\hline \multirow[t]{3}{*}{ Kamar 2} & Pintu & $90 \times 210$ & Pintu & $90 \times 210$ & Pintu & $90 \times 210$ \\
\hline & Jendela & $130 \times 160$ & Jendela & $130 \times 160$ & Jendela & $130 \times 160$ \\
\hline & Roster & $20 \times 20$ & Roster & $20 \times 20$ & Roster & $20 \times 20$ \\
\hline \multirow[t]{2}{*}{ Dapur } & Pintu & $80 \times 205$ & Roster & $50 \times 125$ & Bukaan atas & $60 \times 80$ \\
\hline & Jendela & $65 \times 160$ & $\begin{array}{l}\text { Bukaan dari } \\
\text { ruang } \\
\text { bermain } \\
\text { anak }\end{array}$ & $100 \times 210$ & roster & $20 \times 20$ (3 buah) \\
\hline Kamar Mandi & $\begin{array}{l}\text { Lubang } \\
\text { plafond }\end{array}$ & $40 \times 40$ & $\begin{array}{l}\text { Lubang } \\
\text { plafond }\end{array}$ & $40 \times 40$ & $\begin{array}{l}\text { Lubang } \\
\text { plafond }\end{array}$ & $40 \times 40$ \\
\hline Ruang makan & glassblok & & & & roster & $50 \times 50$ (3 buah) \\
\hline \multirow[t]{3}{*}{ Ruang keluarga } & Pintu & $90 \times 210$ & Pintu & $90 \times 210$ & Bukaan & $200 \times 200$ \\
\hline & & & Jendela & $130 \times 160$ & samping dari & $100 \times 200$ \\
\hline & & & Roster & $20 \times 20$ & $\begin{array}{l}\text { ruang makan } \\
\text { dan ruang } \\
\text { tamu }\end{array}$ & \\
\hline Ruang bermain & & & Void & $200 \times 200$ & & \\
\hline Warung & $\begin{array}{l}\text { Pintu } \\
\text { warung }\end{array}$ & $200 \times 200$ & & & & \\
\hline
\end{tabular}




\section{KESIMPULAN}

Berdasarkan penelitian tentang perubahan tata ruang pada rumah tipe kecil dan pengaruhnya terhadap aspek kesehatan penghuninya, ada beberapa kesimpulan yang didapatkan

1. Perubahan tata ruang pada rumah tipe kecil berdasarkan kebutuhan ruang penunjang aktivitas penghuninya.

2. Aspek kesehatan yang diteliti meliputi pencahayaan, penghawaan dan kelembaban.

3. Pencahayaan berpengaruh terhadap dua hal yaitu aspek fisik dan aspek psikologis. Aspek fisik yang dimaksud bahwa pencahayaan dibutuhkan secara fisik untuk menerangi ruang. Aspek psikologis yang dimaksud adalah pencahayaan akan memberi rasa nyaman untuk beraktivitas pada penghuninya. Ukuran bukaan yang terdapat pada rumah sederhana yang diteliti mempunyai ukuran sesuai dengan standar sehingga matahari dapat masuk untuk menerangi ruangan.

4. Pada rumah tipe kecil, bukaan yang digunakan untuk memasukkan cahaya berfungsi juga untuk sirkulasi udara dan mengurangi udara lembab di dalam rumah.

5. Kelembaban di dalam rumah diakibatkan karena kurangnya cahaya matahari secara langsung yang masuk ke dalam ruangan. $\mathrm{Hal}$ ini disebabkan antara lain karena lubang bukaan kurang besar atau posisi ruang tidak terkena matahari langsung.

\section{UCAPAN TERIMAKASIH}

Penelitian ini dilakukan dengan sumber dana yang dibiayai oleh Kopertis Wilayah III melalui Program Penelitian Hibah Bersaing Tahun Anggaran 2016.

\section{REFERENSI}

[1] Keputusan Menteri Permukiman Dan Prasarana Wilayah Nomor: 403/Kpts/M/2002. Pedoman Teknis Pembangunan Rumah Sederhana Sehat (Rs Sehat). Http://Www.Pu.Go.Id/Satminkal//tjen/Lama/Hu kum/Km403-0211.Pdf.

[2] Manurung, Parmonangan. (2012). Pencahayaan Alami Dalam Arsitektur. Yogyakarta : Penerbit Andi.

[3] Farida, Ratna. Rumah Sehat. Http://Www.Scele.Ui.Ac.ld

[4] Pusat Data Dan Informasi Kementerian Kesehatan Republik Indonesia. (2012). Peta Kesehatan Indonesia Tahun 2010. Http://Www.Depkes.Go.Id

[5] Nurwulandari. (2003). Rumah Hemat Energi. Serial Rumah. Gramedia.

[6] Frick, Heinz Dan Fx Bambang Suskiyatno. (2007). Dasar-Dasar Arsitektur Ekologis. Yogyakarta: Penerbit Kanisius.

[7] Moleong, Lexy. Metode Penelitian Kualitatif. Bandung. Remaja Rosdakarya 